\title{
MODELO DE CONSTRUCTO PARA ANÁLISE DA SUSTENTABILIDADE NA ATIVIDADE LEITEIRA
}

\author{
Construction Model for Sustainability Analysis in Dairy Activity
}

\section{RESUMO}

O objetivo do estudo consistiu em propor um modelo de constructo contendo indicadores voltados para mensurar a sustentabilidade na atividade leiteira. Para tal, elaborou-se um conjunto de indicadores tomando-se como base a literatura, abordando a sustentabilidade nas dimensões econômica, social, ambiental e político institucional. Quanto ao enquadramento metodológico, esta pesquisa pode ser considerada como descritiva, com base em análise documental e foi realizada por meio de abordagem qualitativa, tendo sido utilizada a metodologia Delphi. Então, para atingir o objetivo citado, a lista de indicadores foi enviada a cinco especialistas da cadeia produtiva do leite (diretores, gerentes, presidentes e técnicos de cooperativas) que atuam em atividades de coleta, armazenagem e beneficiamento de produtos derivados de leite. Quanto aos resultados encontrados, o modelo SISB (Sistema de Indicadores Sustentabilidade Bovina) contou com um total de 70 indicadores, sendo 34 indicadores alocados na dimensão econômica, 16 indicadores na dimensão social, 12 indicadores na dimensão ambiental e 8 indicadores voltados à dimensão político institucional. A contribuição deste estudo fundamenta-se no fato de ter compilado vários indicadores dispersos na literatura sobre sustentabilidade e submetê-los ao crivo de especialistas do segmento da bovinocultura leiteira com a intenção de adaptar tais parâmetros ao contexto da atividade leiteira.

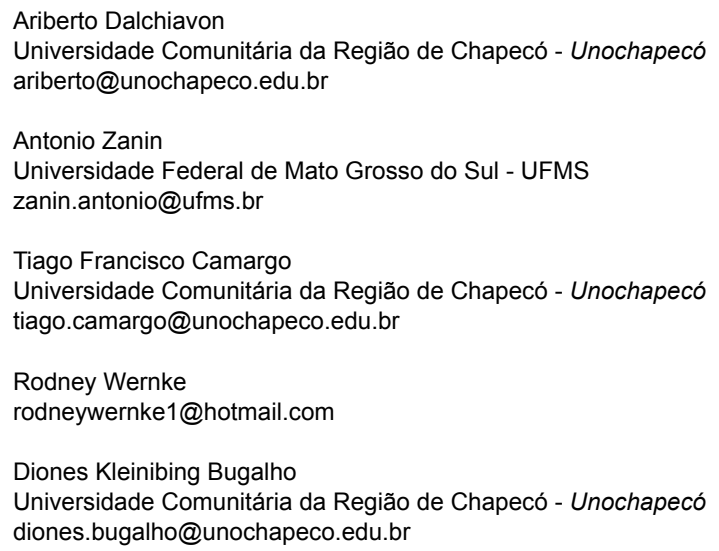

The objective of the study is to propose a construction model that includes indicators aimed at measuring activity in dairy farming. To this end, develop a set of indicators based on the literature, addressing sustainability in the economic, social, environmental and institutional policies. As for the methodological framework, this research can be considered as descriptive, based on documentary analysis and was carried out through a qualitative approach, using the Delphi methodology. Then, in order to achieve the aforementioned objective, a list of indicators was sent to five specialists in the milk production chain (directors, managers, presidents and cooperative technicians) who work in the collection, storage and processing of dairy products. As for the results found, the SISB model (Bovine Sustainability Indicators System) had a total of 70 indicators, of which 34 were allocated to economics, 16 to social indicators, 12 to environmental indicators and 8 to institutional indicators. The contribution of this study is based, in the case of a fact compiled several indicators scattered in the literature on sustainability and submitted them to the criteria of specialists in the dairy cattle segment with the intention of adapting such methods in the context of the dairy activity.

Palavras-chave: Avaliação de sustentabilidade; Cadeia produtiva; Indicadores.

Keywords: Sustainability assessment; Productive chain; Indicators. 


\section{INTRODUÇÃO}

Conforme a Rede Interagencial de Informação para a Saúde - RIPSA (2013), a construção de indicadores é um processo cuja complexidade pode variar desde etapas iniciais de contagem até cálculos mais sofisticados, nos quais se envolvem taxas, razões e proporções, cabendo ao pesquisador constatar o que ele precisa para atingir suas metas. Nesse sentido, os indicadores servem para construção de conhecimento, levando em consideração o contexto pelo qual se propõe a avaliar, a partir da percepção do próprio pesquisador por meio de atividades que identificam, organizam, mensuram, agregam e possibilitam visualizar o impacto das ações e seu gerenciamento (Ensslin, Giffhorn, Ensslin, Petri \& Vianna, 2010).

Belloni, Magalhães e Sousa (2007) consideram que os indicadores servem para explicar a forma de utilização de critérios operacionais, de forma a permitir a análise institucional, considerando as dimensões relativas à percepção, formulação e gestão dos resultados. Os indicadores de sustentabilidade são as ferramentas utilizadas para a medição da mesma. Segundo Barreto (2004), algo que seja sustentável indica algo capaz de ser suportável, duradouro e conservável, apresentando uma imagem de continuidade. Trata-se da emergência de um novo paradigma para orientação dos processos, de uma reavaliação dos relacionamentos da economia e da sociedade com a natureza e do Estado com a sociedade civil.

De acordo com Hallstedt (2017) critérios de sustentabilidade geralmente são desenvolvidos para definir o design de sustentabilidade e, assim, fazer uso de métricas detalhadas, como indicadores. Dessa forma, um critério é definido como uma meta de um aspecto priorizado ou o nível do aspecto que buscamos (por exemplo: nenhum produto químico perigoso usado). Um indicador é definido como uma medida ou fato (qualitativo ou quantitativo), o qual pode indicar o estado ou nível do critério (Sitorus \& Brito-Parada, 2020).

Para Broccardo \& Zicari (2020), a sustentabilidade vive um momento de rompimento de paradigmas, ou seja, passou de um tema discutido apenas no âmbito acadêmico para um tema conhecido como propulsor da criação de valor, sobretudo em pequenos produtores rurais (Zanin, Dal Magro, Kleinibing Bugalho, Morlin, Afonso \& Sztando, 2020) e pequenas empresas (De Camargo, Zanin, Mazzioni, De Moura \& Afonso, 2018) que procuram aliar práticas de sustentabilidade a um método alternativo de produção, tendo por base a relação de trabalho justa e transparente, além de contribuir para melhoria de condições de vida dos produtores de países em desenvolvimento (Sama, Crespo-Cebada, Díaz-Caro, Escribano \& Mesías, 2018). Essa prática produtiva, conhecida como comercio justo informa ao consumidor final que os produtos que estão sendo adquiridos foram obtidos usando sistemas de produção que atingem os objetivos socioambientais (Dragusanu, Giovannucci \& Nunn, 2014; Ramos, Afonso \& Rodrigues, 2020).

Ao correlacionar a sustentabilidade de forma abrangente com a produção da atividade agropecuária, Verona (2008) enfatiza que a diversificação da agricultura tem exigido novas formas de exploração que priorizem a qualidade e o resultado positivo, mas sem agredir o meio ambiente e as condições locais onde os mesmos atuam. Portanto, devem ser buscadas alternativas para um desenvolvimento sustentável, subsidiando a tomada de decisão com ferramentas capazes de medir estas variáveis.

Já a atividade leiteira, por desenvolver outras atividades pecuárias e agrícolas dentro de um mesmo campo de análise, é considerada uma atividade complexa (Yamaguchi, Oliveira \& Martins, 2005). Nesse sentido, Zanin et al. (2020) aduzem que geralmente são várias unidades de negócio relacionadas a um grande negócio, sendo que outras atividades são desempenhadas concomitantemente como a criação de animais, produção de leite, alimentação, sanidade e reprodução, além de produzir a alimentação para os mesmos.

Spies (2014) assevera que a produção de leite no Brasil é uma das cadeias produtivas do agronegócio que tem os maiores ganhos marginais a incorporar em todos os seus elos de produção nos próximos anos. Trata-se de um setor que evoluiu menos em termos de profissionalização e organização do que outras cadeias produtivas, como a produção de frangos de corte e suínos, que hoje já são competitivas mesmo em mercados globalizados. Porém, mesmo que a cadeia produtiva do leite se apresente em um estágio de desenvolvimento menor em relação às demais citadas, esta tem um enorme potencial para melhorar se resolver os problemas que o setor enfrenta.

A partir do exposto, nesta pesquisa se pretende buscar resposta para a seguinte questão de estudo: quais são os indicadores a serem utilizados para avaliação da sustentabilidade na atividade leiteira? Para tal finalidade foi estabelecido o objetivo de propor um modelo de constructo contendo indicadores destinados a avaliar a sustentabilidade na atividade leiteira.

Quanto à justificativa para esse enfoque, Dal Soglio (2013) defende que olhando o comprometimento sustentável futuro, se pode retratar a cadeia agrícola com 
algumas ponderações. Assim, a agricultura familiar deve ter a capacidade de geração de novidades que, se adequadamente utilizadas, poderão gerar formas de organizações produtivas e tecnologias abrangentes para serem utilizadas em diferentes escalas e nos diferentes subsistemas dos agroecossistemas.

Além disso, a percepção e importância da sustentabilidade há muito tempo deixa seu nicho acadêmico e se torna parte integrante do mundo dos negócios (LüdekeFreund, Freudenreich, Schaltegger, Saviuc \& Stock, 2017), refletindo, assim, um ambiente de negócios em constante mudança, aumentando o grau de envolvimento das partes interessadas em sustentabilidade no debate público (Freeman \& Dmytriyev, 2017). De fato, mais empresas devem integrar a sustentabilidade em suas atividades comerciais (Evans, 2012) em busca do pleno equilíbrio entre os impactos econômicos, ambientais e sociais, se tornando fonte de inovação e rentabilidade (Baumgartner, 2014).

Ademais, conforme Dal Soglio (2013), em relação à sustentabilidade da atividade leiteira percebe-se que há uma necessidade de oferecer suporte a este setor, que é muito representado pela agricultura familiar e que tem grande importância em termos de sua contribuição para o desenvolvimento da economia do país, bem como por auxiliar na permanência de grande contingente de brasileiros na atividade especificamente e no campo em geral.

\section{REFERENCIAL TEÓRICO}

Nesta seção apresenta-se o referencial teórico do estudo que serviu de sustentação para o desenvolvimento da pesquisa.

\subsection{Sustentabilidade}

O termo "sustentabilidade" vem do latim sustentare e significa suster, suportar, conservar em bom estado, manter ou resistir. Assim, assume-se que sustentável é tudo que é capaz de ser suportado, mantido (Deponti \& Almeida, 2001). Por outro prisma, o conceito de sustentabilidade deve ser uma construção consensual entre indivíduos, organizações e nações, pois as pessoas não são resistentes às mudanças em si, mas são resistentes àquelas mudanças que lhes são impostas (Capra, 2006).

$\mathrm{Na}$ mesma direção, Banerjee (2002) traduz o conceito de sustentabilidade como a conciliação do crescimento econômico com a manutenção do meio ambiente, além de um foco na justiça social e no desenvolvimento humano, bem como pela distribuição e utilização equilibrada de recursos com um sistema de igualdade social. Por sua vez, Garcia (2012) afirma que a sustentabilidade decorre de sustentação, a qual, por sua vez, é relacionada à manutenção, à conservação, à permanência, à continuidade e assim por diante.

Para encaixar o novo perfil de produção global, as organizações precisam modificar seus processos de produção ou mesmo reestruturar todo o negócio quando necessário (Sachs, 2009). Isto implica a construção de sistemas de produção que causem menos impactos negativos e contribuir para ações e incentivos para a recuperação de áreas degradadas, inovando com produtos e serviços que melhoram a sustentabilidade, especialmente em termos de desempenho ambiental das indústrias (De Camargo et al., 2018).

Já para Garcia e Garcia (2014) é necessário ter em mente que sustentabilidade é uma dimensão ética e que a mesma trata de uma questão existencial, pois é algo que busca garantir a vida, não estando simplesmente relacionada à natureza, mas relaciona o indivíduo com todo o ambiente a sua volta. De forma semelhante, Zanin, Dal Magro, Mazzioni \& Afonso (2019) enfatizam que a sustentabilidade também está calcada na observância da interdependência de vários elementos da sociedade entre si e em relação ao tecido social. Assim, sustentabilidade é o reconhecimento das necessidades e interesses das outras partes (grupos comunitários, instituições educacionais e religiosas, força de trabalho e público), não esgarçando, mas visando reforçar a rede de relacionamentos que as mantêm integradas (Broccardo \& Zicari, 2020). Portanto, a sustentabilidade é o equilíbrio dinâmico com o outro e com o meio ambiente, é a harmonia entre os diferentes (Gadotti, 2012).

Giordano (2005) menciona que as atividades agrícolas são reconhecidamente causadoras de problemas ao meio ambiente. Assim, iniciativas que busquem a produção agrícola, de forma sustentável, são bem-vindas para que sejam minimizados os problemas enfrentados pelos produtores, principalmente quanto à colocação dos produtos no mercado, seja por logística, custos ou escala.

Vilela et al. (2002) relatam que, para ter melhores condições de competividade na atividade leiteira promovendo a sustentabilidade, é necessário que haja o desenvolvimento de ações voltadas à especialização deste setor produtivo. Nesse sentido, argumentam que somente se conseguirá a sustentabilidade na cadeia leiteira através da profissionalização dos gestores ligados diretamente a este setor primário. 


\subsection{Dimensão Econômica}

O pilar econômico, segundo Elkington (2012, 2020), evidencia-se fundamentalmente nos resultados financeiros da organização, sendo geralmente reconhecido como capital físico e financeiro, mas estende-se para o capital humano, intelectual, natural e social. Destarte, a sustentabilidade econômica apresenta uma análise mais complicada do que a ambiental, pois o conceito restringe o crescimento econômico e a eficiência produtiva. Portanto, essa concepção diverge do sistema capitalista que afirma que o crescimento deve ser ilimitado, pois isso traria prejuízos para a dimensão ambiental (Foladori, 2002).

Cajazeira (2009) afirmam que a sustentabilidade econômica possibilita a alocação e gestão eficiente dos recursos produtivos, bem como um fluxo regular de investimentos públicos e privados. Por seu turno, Silva (2013) salienta que a sustentabilidade econômica pode ser alcançada pela alocação eficiente dos recursos e pelas modificações dos atuais mecanismos de orientação dos investimentos.

Já Daly (2014) argumenta que o crescimento sustentável é algo impossível, e afirma que para haver crescimento econômico com sustentabilidade, seria necessária uma economia estacionária ou com crescimento nulo. Ainda o autor fala que a insustentabilidade do crescimento atual é que traz a urgência do desenvolvimento sustentável, e assim sendo, para todo o crescimento há um limite que ultrapassado não o torna sustentável.

A sustentabilidade econômica abrange alocação e distribuição eficiente dos recursos naturais dentro de uma escala apropriada, ou seja: o conceito de desenvolvimento sustentável, observado a partir da perspectiva econômica, vê o mundo em termos de estoques e fluxo de capital (Zanin, Dal Magro, Mazzioni \& Afonso, 2019). Contudo, esta visão não está restrita apenas ao convencional capital monetário ou econômico, mas está aberta a considerar capitais de diferentes tipos, incluindo o ambiental e/ou natural, o capital humano e o capital social, além disso, o entendimento do pilar econômico passa pelos conceitos de capital físico, financeiro, humano e intelectual, mas que a longo prazo é necessário integrar também o capital social e o capital natural (Elkington, 2012).

\subsection{Dimensão Social}

A dimensão social do desenvolvimento está relacionada à busca por uma civilização com maior igualdade na distribuição de renda, de maneira que favoreça a inclusão social com distribuição de renda justa, vida decente e acesso aos recursos e serviços sociais (Sachs,
2009). Nessa direção, Cajazeira (2009) aduz que a sustentabilidade social trata da consolidação de processos que promovem a equidade na distribuição dos bens e da renda para melhorar substancialmente os direitos e condições de amplas massas da população e reduzir as distâncias entre os padrões de vida das pessoas.

O pilar social contempla as questões de bem-estar social das pessoas e dos públicos das organizações, tanto em relação aos impactos sociais organizacionais, quanto aos ligados às demandas que necessitam da intervenção organizacional, vislumbrando a diminuição das desigualdades sociais, o respeito e o envolvimento das comunidades no negócio (Elkington, 2012).

Entretanto, Wiesenfeld (2003) alerta para o risco de que a dimensão social seja reduzida ao discurso, pois a fragilidade a despeito dos avanços na inclusão e compreensão da dimensionalidade vem da falta de precisão nos seus conceitos acarreta uma distância entre a teoria e a prática, o que implica também na falta de estratégias metodológicas que garantam sua incorporação e sua aplicação. Com isso, a percepção é que a dimensão social está atrelada entre as demais dimensões (ambiental, econômica, institucional e outras), mas é a mais difícil de ser mensurada.

Por outro lado, Magis e Shinn (2008) afirmam que a sociedade deve ser sustentada por direito próprio e, por isso, a sustentabilidade social tem papel fundamental na sustentabilidade como um todo, uma vez que são os seres humanos, individual ou coletivamente, que irão determinar níveis de bem-estar econômico ou ambiental. De modo semelhante, Larsen (2008) argumenta que a sustentabilidade deve pensar primeiro nas pessoas, como elas fazem suas escolhas e suas respectivas consequências.

Nesse sentido, a dimensão social tem como objetivo principal garantir acesso a bens e serviços de qualidade a todas as pessoas, proporcionando-lhes uma vida de qualidade baseada no desenvolvimento com liberdade. Para tanto, requer que se movam as principais fontes de privação de liberdade: pobreza e tirania, carência de oportunidades econômicas e destruição social sistemática, negligência dos serviços públicos e intolerância ou interferência excessiva de Estados repressivos (Sen, 2018).

\subsection{Dimensão Ambiental}

Pela concepção de Nascimento (2012) a dimensão ambiental "supõe que o modelo de produção e consumo seja comparável com a base material em que se assenta a economia, como subsistema do meio natural, sendo que a produção e o consumo garantem a auto reparação dos 
ecossistemas. Portanto, a dimensão ambiental está focada na ecoeficiência, que significa o fornecimento de bens e serviços a preços competitivos, satisfazendo as necessidades humanas e, em contrapartida, proporcionando qualidade de vida e reduzindo a um nível suportável pelo planeta os impactos ecológicos e a intensidade do consumo de recursos durante o ciclo de vida (Elkington, 2012).

Ao tratar da dimensão ambiental, Cajazeira (2009) cita que ela se refere às ações que evitam danos ao meio ambiente como: $(i)$ a redução da emissão de poluentes; (ii) a preservação da biodiversidade e (iii) a substituição do consumo de recursos não renováveis por processos renováveis.

De forma complementar, Elkington (2012) comenta que a sustentabilidade ambiental pode ser conquistada através da preservação (ou recuperação da capacidade) de recursos do planeta por meio da evolução tecnológica socialmente justa e economicamente viável. Para tal finalidade cabe, então, cogitar iniciativas relacionadas com restrições do consumo de combustíveis fósseis, redução do volume de resíduos e da poluição, bem como da redução/ racionalização do consumo pelos países ricos.

Do mesmo modo, Sachs (2009) assevera que a sustentabilidade econômica deve ser buscada para promover a reprodução social do homem, sendo que apenas as soluções que promovam crescimento econômico com impactos positivos em termos socioambientais, merecem a denominação de desenvolvimento sustentável (Ramos, Afonso \& Rodrigues, 2020).

\subsection{Dimensão Político Institucional}

Spangenberg, Pfahl e Deller (2002) mencionam que a sustentabilidade institucional é uma meta política composta, pois os critérios sociais, ambientais e econômicos devem ser considerados com igual importância. Dessa forma, em uma sociedade sustentável, não se aceita a degradação ambiental, a violação da dignidade humana pela pobreza (ou outras ameaças) e nem a bancarrota pública ou privada, e acaba por enquadrar também o conceito da sustentabilidade institucional (Lima, 2005).

Para Silva, Cheaz \& Romero (2001) a sustentabilidade institucional remete ao conjunto de todas as regras formais e informais que moldam a natureza de sua identidade, influenciam a intensidade e qualidade de sua dinâmica e direcionam os compromissos associados ao seu propósito. Entre estas "regras do jogo" se encontram as leis, políticas, premissas, enfoques, planos, prioridades, estratégias, normas, mecanismos institucionais etc. Defendem, ainda, que a sustentabilidade institucional corresponde à existência, em um país, região, estado ou município, do arcabouço referente às políticas públicas de meio ambiente ligadas ao planejamento, estratégias e ações específicas para a gestão que garanta a qualidade ambiental no território respectivo.

De acordo com o Instituto Brasileiro de Geografia e Estatística (IBGE, 2012), a dimensão institucional refere-se à orientação política, capacidade e esforço desempenhado por governos e pela sociedade na execução das mudanças requeridas por um desenvolvimento sustentável efetivo. Assim como a elaboração da ONU, o IBGE também utiliza os temas arcabouço institucional e capacidade institucional na sistematização de indicadores nessa dimensão.

Porém, Van Bellen (2006) assinala que a ausência de indicadores não triviais na dimensão institucional do desenvolvimento sustentável deve ser observada, uma vez que pode ser considerado um dos maiores problemas nos projetos de indicadores de desenvolvimento sustentável.

\subsection{Estudos Anteriores Assemelhados}

A sustentabilidade tem sido um tema muito debatido em diversas instâncias acadêmicas e não acadêmicas. No que tange às atividades agropecuárias já existem diversas pesquisas divulgadas nas últimas décadas. Contudo, no âmbito da atividade leiteira (que costuma ser embutida dentro das atividades agropecuárias) a literatura a respeito já é bem mais recente e mais escassa. Nesse rumo, na Tabela 1 são elencados estudos que discorreram sobre a sustentabilidade pelas perspectivas que os autores respectivos consideram ser as ideais para ter uma dimensão mais justa e perfeitamente equalizada.

Como visto, no rol de publicações mencionadas não foi encontrado trabalho com o objetivo de propor um conjunto de indicadores destinados a avaliar a sustentabilidade na atividade leiteira. Com isso, considera-se que há uma lacuna de pesquisa que merece ser mais bem explorada, como pretendido neste estudo.

\section{METODOLOGIA}

Quanto ao enquadramento metodológico, é pertinente classificar esta pesquisa como descritiva, com base em análise documental e tendo sido realizada por meio de abordagem qualitativa. Além disso, convém destacar que a metodologia utilizada foi a Delphi, cuja escolha, segundo Wright e Giovinazzo (2000), deve se dar em função das características do estudo, tais como a inexistência de dados históricos, a necessidade de abordagem interdisciplinar e as perspectivas de mudanças estruturais no setor. 
TABELA 1 - Estudos Assemelhados

\begin{tabular}{|c|c|c|}
\hline Autoria/Ano & Tema explorado & Dimensão aplicada \\
\hline Gomes (2005) & $\begin{array}{c}\text { O estudo procurou encontrar indicadores de uma possível } \\
\text { sustentabilidade nas lógicas produtivas da agricultura familiar das } \\
\text { comunidades rurais de Pedra Branca, Bom } \\
\text { Retiro e Bocaina, no município de Caldas (MG) }\end{array}$ & Social e Ambiental \\
\hline $\begin{array}{l}\text { Rempel et al. } \\
\quad(2012)\end{array}$ & $\begin{array}{c}\text { Proposta metodológica para avaliação da sustentabilidade ambiental } \\
\text { de propriedades produtoras de leite }\end{array}$ & Ambiental \\
\hline Silva (2013) & $\begin{array}{l}\text { Analisou a sustentabilidade da atividade bovina leiteira no município } \\
\qquad \text { de Pombal (PB) }\end{array}$ & $\begin{array}{l}\text { Institucional/Tecnológica, Social, } \\
\text { Ambiental e Econômica }\end{array}$ \\
\hline Bedoya (2015) & $\begin{array}{l}\text { Analisou a sustentabilidade da produção de leite na principal bacia } \\
\text { leiteira do brasil }\end{array}$ & Econômico, Ambiental e Social \\
\hline Ribeiro (2015) & $\begin{array}{c}\text { Desenvolvimento rural sustentável e agricultura familiar: diagnóstico } \\
\text { participativo de indicadores econômicos, sociais e ambientais da } \\
\text { região oeste do Paraná. }\end{array}$ & Econômico, Ambiental e Social \\
\hline Silva (2015) & $\begin{array}{l}\text { Avaliação da sustentabilidade dos agroecossistemas de agricultores } \\
\text { familiares que atuam na feira-livre de Pato Branco (PR) }\end{array}$ & Econômico, Ambiental e Social \\
\hline Ahlert (2016) & $\begin{array}{c}\text { Sistema de indicadores para avaliação da sustentabilidade de } \\
\text { propriedades produtoras de leite }\end{array}$ & Econômico, Ambiental e Social \\
\hline $\begin{array}{l}\text { Di Domênico et } \\
\text { al. }(2017)\end{array}$ & $\begin{array}{l}\text { Objetivou identificar o índice de sustentabilidade ambiental da } \\
\text { atividade de produção leiteira em propriedade rural da região Oeste de } \\
\text { Santa Catarina }\end{array}$ & Ambiental \\
\hline $\begin{array}{l}\text { De Camargo et al. } \\
\qquad(2018)\end{array}$ & $\begin{array}{c}\text { Procurou identificar o nível de sustentabilidade } \\
\text { das granjas suinícolas Oeste de Santa Catarina, através de } \\
\text { um conjunto de indicadores estruturados em } 4 \text { dimensões da } \\
\text { sustentabilidade. }\end{array}$ & $\begin{array}{l}\text { Econômica, Ambiental, Social e } \\
\text { Política Espacial. }\end{array}$ \\
\hline
\end{tabular}

Fonte: elaborado pelos autores

A técnica Delphi conforme Spínola (p. 1984) é definida como a técnica de processo grupal que tem por finalidade obter, comparar e direcionar o julgamento de peritos para um consenso de um tópico em particular, promovendo a convergência de opiniões.

Para construção dos indicadores a serem utilizados nesta pesquisa, utilizou-se de pesquisas bibliográficas sobre a temática estudada, com base em informações relevantes e publicadas por órgãos regulamentadores e por pesquisadores com materiais publicados sobre aspectos relativos à sustentabilidade na temática específica da bovinocultura e áreas afins como sustentabilidade de maneira mais ampla. Neste sentido, os estudos de Verona (2008), Peruzatto (2009), Rempel et al. (2012) e Ahlert (2016), permitiram identificar como respostas possíveis indicadores relevantes para a temática, observando um alinhamento dentro de áreas específicas da sustentabilidade as quais foram denominadas "dimensões" da sustentabilidade.

Para ser operacionalizado, o que foi batizado como sendo Sistema de Indicadores de Sustentabilidade para Bovinocultura (SISB), foi desenvolvido um modelo de cálculo com atribuição de peso para o conjunto de 70 indicadores propostos, os quais dimensionam os níveis de sustentabilidade para atividades de bovinocultura na propriedade rural.

Para a construção do Modelo SISB e os seus indicadores, utilizou-se do método Delphi, tendo a participação de cinco especialistas da temática pesquisada, que atuam como diretores, gerentes, presidentes e técnicos que exercem funções de gerência ou supervisores responsáveis por unidades de processamento de leite, tendo como objetivo validar os indicadores propostos, bem como sugerir e ou eliminar indicadores. Para validação do conjunto de indicadores propostos por meio da literatura, os mesmos foram enviados aos especialistas por meio de questionários, retornando com a sugestão da inclusão de 13 indicadores e a alteração de 6 indicadores. Para a segunda rodada, incluiu-se os novos indicadores e alterações sugeridas pelos especialistas no retorno da primeira rodada, reenviado aos mesmos especialistas, os quais validaram o modelo 
de indicadores proposto com as correções, inclusões e exclusões de indicadores, conforme seu nível de expertise prática, de legislações ambientais e políticas institucionais, conjuntura econômica, estrutura social dos produtores e da atividade. Com esse procedimento foram corrigidos/ alterados 19 indicadores para atender a orientação dos especialistas consultados nesta fase de preparação do instrumento de pesquisa.

$\mathrm{Na}$ fase seguinte (terceira rodada do Método Delphi), o instrumento recebeu nova avaliação de especialistas de acordo com os parâmetros “ 0 , 1, 2, 3 e 4" quanto à relevância de cada indicador para a atividade visada, sendo que esta fase foi designada como PE1 (pesquisa especialista). Ao mesmo tempo os especialistas avaliaram cada indicador quanto à amplitude de seus impactos para a sustentabilidade da atividade, os indicadores também foram avaliados pelos critérios “ $0,5,1,1,5$ e 2 ”, tendo sido esta etapa designada como A1 (avaliação especialista). Nesses dois procedimentos, todas as respostas dos especialistas foram tabuladas individualmente e realizadas suas médias coletivas quanto aos critérios "PE1" e "A1".

Desse modo, o modelo proposto inovou frente aos demais modelos apresentados pela literatura, quando realizou a média do peso das respostas de cada indicador com base na opinião dos especialistas e dos produtores. Assim, este resultado foi somado à média identificada do impacto da amplitude deste indicador para sustentabilidade da atividade conforme avaliação dos especialistas (A1).

Na sequência, para identificação efetiva do peso de cada indicador por meio do modelo em tela, foi necessário fazer o somatório dos resultantes da multiplicação dos valores combinados da pesquisa, em avaliação do produtor (PP1), do especialista (PE1) e pela avaliação dos especialistas quanto à amplitude de cada indicador avaliado (A1); a fórmula do modelo resultou na seguinte equação: $\mathrm{SISB}=(((\mathrm{PP} 1 * \mathrm{PE} 1) / 2)+\mathrm{A} 1)$, o que resultou no peso de cada indicador no modelo. Porém, o modelo completo é composto por setenta (70) indicadores distribuídos em quatro dimensões: (i) Econômica, com 34 indicadores; (ii) Social, com 16 indicadores; (iii) Ambiental, com 12 indicadores e (iv) Político institucional, com 8 indicadores.

Desta maneira, para se identificar quanto cada dimensão representa de peso na avaliação geral da sustentabilidade através do modelo ora proposto, foi necessário, com base na média do peso final de cada indicador, calcular os procedimentos estatísticos da Entropia de cada indicador do modelo, fazendo com que o peso de cada indicador dentro da dimensão torne-se o menos subjetivo possível. Desta forma, procurou-se eliminar os riscos de "achismos" ou preferências que pudessem causar distorções nos resultados do modelo.

Após apurados os pesos de cada dimensão e de cada indicador por meio das técnicas estatísticas da Entropia, o peso médio final atribuído pelos Especialistas e pelos Produtores devem ser multiplicados pelo peso de seu indicador atribuído pela Entropia. Esta é a execução do cálculo da avaliação geral do indicador, que por sua vez permite o cálculo da eficiência dos indicadores na dimensão e que formam o somatório das quatro dimensões (DE; DS; DA; DPI), resultando na avaliação geral da propriedade em um dos quatro níveis de sustentabilidade evidenciados.

Assim sendo evidencia-se no Quadro 1 a pontuação mínima e máxima em cada dimensão.

Após a apuração do cálculo da sustentabilidade individualizada por dimensão, efetua-se a soma da pontuação geral do modelo proposto, permitindo então chegar a um determinado nível de sustentabilidade geral da propriedade pesquisada.

\section{RESULTADOS E DISCUSSÕES}

Nesta seção faz-se a descrição dos resultados obtidos sobre o objeto do estudo, que são decorrentes da validação dos indicadores elencados nos questionários pelos especialistas consultados, conforme as dimensões consideradas. O Quadro 3 evidencia o conjunto de indicadores relacionados com a dimensão "Econômica".

QUADRO 1 - Pontuação por dimensão

\begin{tabular}{|cccccccccc|}
\hline \multicolumn{8}{|c|}{ Sistema de Indicadores de Sustentabilidade Bovina - SISB } \\
\hline \multicolumn{7}{|c}{ Por dimensão (Pontuação mínima e máxima) } \\
\hline \multicolumn{7}{|c}{ DE } & \multicolumn{7}{c}{ DS } & \multicolumn{2}{c|}{ DA } & \multicolumn{2}{c|}{ DPI } & GERAL \\
\hline Mínima & Máxima & Mínima & Máxima & Mínima & Máxima & Mínima & Máxima & Mínima & Máxima \\
0,00 & 5,55 & 0,00 & 1,33 & 0,00 & 0,69 & 0,00 & 2,43 & 0,00 & 10,00 \\
\hline
\end{tabular}

Fonte: Elaborado pelos autores 
QUADRO 2 - Classificação dos níveis de sustentabilidade

\begin{tabular}{|c|c|c|}
\hline \multicolumn{3}{|c|}{ Sistema de Indicadores de Sustentabilidade Bovina - SIS } \\
\hline \multicolumn{2}{|c|}{ Geral } & \multirow{2}{*}{$\begin{array}{l}\text { Classificação do nível de } \\
\text { Sustentabilidade }\end{array}$} \\
\hline Mínimo & Máximo & \\
\hline 7,5 & 10 & Sustentável \\
\hline 5 & 7,49 & Sustentabilidade Ameaçada \\
\hline 2,5 & 4,99 & Em busca da Sustentabilidade \\
\hline 0 & 2,49 & Insustentável \\
\hline
\end{tabular}

Fonte: Elaborado pelos autores

O Quadro 3 apresentou os indicadores voltados à produtividade e renda, grau de endividamento, serviços básicos disponíveis, evolução tecnológica e gestão do empreendimento. Todos os itens mencionados no Quadro 3 foram segregados em outras áreas que possuem estreita relação e importância com a dimensão econômica, sendo que no estudo realizado para esta dimensão foi atribuído um número maior de indicadores. Com isso, espera-se aferir convenientemente os principais aspectos voltados à Dimensão Econômica das propriedades que atuam no segmento visado.

Quanto à mensuração dos fatores ligados à Dimensão Social, o rol de indicadores priorizados neste estudo está sintetizado no Quadro 4.

Na Dimensão Social, conforme relatado no Quadro 4 , foram abrangidas questões concernentes à qualidade de vida, aos serviços de educação e saúde, às condições de moradia, aos acessos à telecomunicações e à energia elétrica, à seguridade social e ao lazer. Com base nessa lista de aspectos, considera-se que os principais pontos relativos a esta dimensão possam ser enfocados.

A terceira dimensão priorizada neste estudo é a ambiental, cujos indicadores prioritários estão elencados no Quadro 5.

O exame detido do Quadro 5 revela que na Dimensão Ambiental os indicadores estão mais voltados para a destinação de dejetos e para o uso e exploração de APPs, bem como discorrem a respeito do uso de agrotóxicos, da reserva legal, da água, de queimadas e do solo, além do controle da erosão.

A quarta e última dimensão utilizada foi a Político Institucional, conforme detalhamento expresso no Quadro 6.

Por fim nos indicadores da dimensão político institucional os indicadores selecionados versam sobre políticas de gestão ambiental, planejamento estratégico, gestão e disponibilidade de recursos hídricos, assistência técnica, crédito, cursos e tecnologia.
Tendo em vista as quatro dimensões abrangidas e o rol dos respectivos indicadores que prestarão suporte ao desenvolvimento e validação deste método de avaliação que permite com facilidade seus usuários identificar os níveis de sustentabilidade para propriedades que possuem a cultura de bovinos sendo que tal expertise para este setor especifico pode ser considerado inédito com abordagem estatística evitando o subjetivismo para atribuições de pesos e valores dos indicadores.

Contribuem com este entendimento os estudos de Kimpara, Zadjband \& Valentini (2010) quando aduzem que diversos métodos já foram e estão sendo aprimorados para se avaliar a sustentabilidade dos cultivos e têm sido crescentemente aplicados em várias atividades, inclusive na produção animal. Conforme estes autores os métodos mais utilizados para se medir a sustentabilidade são: análise do ciclo de vida, análise energética, pegada ecológica, conjunto de indicadores e resiliência, os quais divergem entre si desde a definição que adotam para o termo "sustentável", abarcando tanto sua concepção quanto as diferenças na escolha dos dados que serão obtidos e nas variáveis que serão medidas.

Diante deste exposto espera-se que esta pesquisa contribua para o conhecimento e a internalização do desenvolvimento e utilidade da método SISB, desenvolvido através da técnica Delphi que considerou todas as contribuições dos especialistas e produtores envolvidos neste estudo, que foi fundamentado e compilado após pesquisas de estudos anteriores, se consolidando pelo filtro de vários indicadores dispersos na literatura sobre sustentabilidade (Ahlert, 2016; Silva, 2015; Rempel et al., 2012; Peruzatto, 2009; Verona, 2008) os quais formam submetidos ao crivo de especialistas do segmento da bovinocultura leiteira com a intenção de adaptar tais parâmetros ao contexto desta atividade agrícola.

O uso de técnicas estatísticas a modelos de avaliação e tomada de decisão, torna o modelo mais consistente e menos subjetivo ao incorporar o uso das técnicas da Entropia para determinação dos pesos de avaliação dos indicadores e das dimensões além do uso do Topsis como auxílio no ranqueamento da matriz decisória ideal, por meio do coeficiente de similaridade que permite gerar um ranking, que apresentou-se muito útil no ordenamento para a decisão, estatisticamente mais ideal. A Entropia pode ser aplicada ao (SISB) para verificar as incertezas informacionais que cada indicador estava trazendo ao modelo. Neste sentido a técnica mostrou-se muito eficaz, pois "ajustou" os pesos dos 70 indicadores. 
QUADRO 3 - Indicadores da Dimensão Econômica

\begin{tabular}{|c|c|c|c|}
\hline & DIMENSÃO ECONÔMICA: 34 INDICADORES (Adaptado de Ahlert, 2016) & Mínimo & Máximo \\
\hline \multicolumn{4}{|c|}{ PRODUTIVIDADE E RENDA } \\
\hline 1 & $\begin{array}{l}\text { Qual a relação custo/benefício do negócio comparando investimento (em dinheiro e trabalho), } \\
\text { produção e renda no seu estabelecimento. }\end{array}$ & 0 & 10 \\
\hline 2 & Pretensão para os próximos anos quanto à produção no seu estabelecimento & 0 & 10 \\
\hline 3 & A consideração atualmente, com relação à renda global gerada no estabelecimento & 0 & 10 \\
\hline \multicolumn{4}{|c|}{ GRAU DE ENDIVIDAMENTO } \\
\hline 4 & Dívida anual em relação à renda $(\%)$ & 0 & 10 \\
\hline \multicolumn{4}{|c|}{ SERVIÇOS BÁSICOS DISPONÍVEIS NO IMÓVEL RURAL } \\
\hline 5 & Serviços básicos disponíveis no estabelecimento (residência). Qualidade de moradia & 0 & 10 \\
\hline 6 & Saneamento básico & 0 & 10 \\
\hline 7 & Energia elétrica na moradia & 0 & 10 \\
\hline 8 & Abastecimento de água tratada & 0 & 10 \\
\hline 9 & Qualidade do acesso à propriedade & 0 & 10 \\
\hline 10 & Acesso regular ao transporte público & 0 & 10 \\
\hline 11 & Telefone (fixo ou celular) & 0 & 10 \\
\hline 12 & Acesso à internet & 0 & 10 \\
\hline 13 & Acesso ao serviço de saúde & 0 & 10 \\
\hline 14 & Coleta pública de lixo & 0 & 10 \\
\hline \multicolumn{4}{|c|}{ EVOLUÇÃO TECNOLÓGICA } \\
\hline 15 & Qual o grau de melhoria na produção de leite em sua propriedade & 0 & 10 \\
\hline 16 & Qualidade geral das instalações rurais (galpão, energia elétrica etc.) & 0 & 10 \\
\hline 17 & Qualidade geral das máquinas e equipamentos & 0 & 10 \\
\hline 18 & Condições adequadas de conforto para os animais & 0 & 10 \\
\hline 19 & Controle da nutrição animal & 0 & 10 \\
\hline 20 & Monitoramento da sanidade animal e da qualidade de leite no rebanho & & 10 \\
\hline 21 & Higiene na obtenção e conservação do leite (piquete de espera, sala de ordenha etc.) & 0 & 10 \\
\hline 22 & Realiza manejo de pastagem & 0 & 10 \\
\hline 23 & Faz rotação de culturas & 0 & 10 \\
\hline 24 & Possui estratégias de reserva de alimentos (ensilagem, fenação etc.) & & 10 \\
\hline \multicolumn{4}{|c|}{ GESTÃO DO EMPREENDIMENTO } \\
\hline 25 & Realiza atividades de gestão do empreendimento & 0 & 10 \\
\hline 26 & Recebe orientação de técnicos quanto a manejo e melhores práticas (assistência técnica) & 0 & 10 \\
\hline 27 & Tem acesso a fontes de financiamento para custeio e investimentos & 0 & 10 \\
\hline 28 & Participa de cursos (palestras) de curta duração direcionado às atividades & 0 & 10 \\
\hline 29 & Promove a capacitação e formação dos integrantes & 0 & 10 \\
\hline 30 & Realiza planejamento e controle financeiro & 0 & 10 \\
\hline 31 & Calcula custos de produção das atividades & 0 & 10 \\
\hline 32 & Utiliza ferramentas de informatização da gestão da propriedade rural & 0 & 10 \\
\hline 33 & Participa em associação (cooperativa, sindicato etc.) de produtores/agricultores & 0 & 10 \\
\hline 34 & Regularização ambiental (uso da água, RP, APP e licenciamento etc.) & 0 & 10 \\
\hline
\end{tabular}

Fonte: elaborado pelos autores 
DALCHIAVON, A. et al.

QUADRO 4 - Conjunto de Indicadores da dimensão social

\begin{tabular}{|cccc|}
\hline & DIMENSÃO SOCIAL: 16 INDICADORES (Adaptado de Silva, 2015) & Mínimo & Máximo \\
\hline 1 & Como você avaliaria sua qualidade de vida? & 0 & 10 \\
2 & Como você avalia sua participação em sindicatos, cooperativas, associações etc.? & 0 & 10 \\
3 & Quão satisfeito(a) você está com sua saúde? & 0 & 10 \\
4 & Quão satisfeito(a) você está com o acesso a serviços de educação? & 0 & 10 \\
5 & Qual o grau de escolaridade do agricultor? & 0 & 10 \\
6 & Quão satisfeito(a) você está com o acesso a serviços médicos? & 0 & 10 \\
7 & Quão satisfeito(a) você está com as estradas e acessos em geral? (pavimentação, situação das estradas etc.) & 0 & 10 \\
8 & Quão satisfeito(a) você está com as condições da moradia que possui? & 0 & 10 \\
9 & Quão satisfeito(a) você está com os meios de comunicação? (telefone e internet) & 0 & 10 \\
10 & Quão satisfeito(a) você está com o acesso ao lazer? (salão de festas, campos de futebol, clube etc.) & 0 & 10 \\
11 & Quão satisfeito(a) você está com os serviços de energia elétrica? & 0 & 10 \\
12 & Quão satisfeito(a) você está com a política de seguridade social? (aposentadoria, auxílio-doença etc.) & 0 & 10 \\
13 & Quão satisfeito(a) você está com a socialização e troca de experiências entre os agricultores? & 0 & 10 \\
14 & Quão satisfeito(a) você está com o dinheiro que possui para suas necessidades? & 0 & 10 \\
15 & Quão satisfeito(a) você está com sua aparência física? & 10 \\
16 & Com que frequência você tem sentimentos negativos, tais como mau humor, desespero, ansiedade, depressão? & 0 & 10 \\
\hline
\end{tabular}

Fonte: elaborado pelos autores

QUADRO 5 - Conjunto de indicadores dimensão ambiental

\begin{tabular}{|lccc|}
\hline & $\begin{array}{c}\text { DIMENSÃO AMBIENTAL: 12 INDICADORES } \\
\text { (Rempel et al., 2012 e Verona, 2008). }\end{array}$ & Mínimo & Máximo \\
\hline 1 & Armazenamento de dejetos sólidos & 0 & 10 \\
2 & Armazenamento de dejetos líquidos & 0 & 10 \\
3 & Exploração de áreas destinadas a APPs & 0 & 10 \\
4 & Destinação de uso das APPs & 0 & 10 \\
5 & Utilização de fertilizantes químicos e agrotóxicos & 0 & 10 \\
6 & Armazenamento de embalagens de agrotóxicos & 0 & 10 \\
7 & Percentual de vegetação nativa para averbação em reserva legal & 0 & 10 \\
8 & Fontes de água & 0 & 10 \\
9 & Declividade do terreno & 0 & 10 \\
11 & Em que medida efetua controle da erosão do solo & 0 & 10 \\
12 & Diversidade de cobertura no uso da terra & 0 & 10 \\
\hline
\end{tabular}

Fonte: elaborado pelos autores

Adicionalmente, com os ajustes recomendados pelos especialistas, os questionários foram também validados pela aplicação efetiva destes junto ao um conjunto de produtores rurais, o que possibilitou a identificação da intensidade de uso ou não, da prática referenciada em cada indicador por cada um destes agentes da cadeia produtiva em lume. Neste sentido, o SISB demonstrou ser válido para os objetivos pretendidos que é a avaliação dos níveis de sustentabilidade de propriedades rurais produtoras de leite, caracterizando-se pela flexibilidade na manutenção e alteração dos pesos e critérios, relevantes para a prática e manutenção da atividade da bovinocultura. 
QUADRO 6 - Conjunto de Indicadores da Dimensão Político Institucional

\begin{tabular}{|lcccc|}
\hline \multicolumn{5}{|c|}{ DIMENSÃO POLÍTICO } \\
INSTITUCIONAL: 8 & Mínimo & Máximo \\
& $\begin{array}{c}\text { INDICADORES } \\
\text { (Adaptado de Peruzatto, 2009) }\end{array}$ & & \\
\hline 1 & Políticas de gestão ambiental & 0 & 10 \\
2 & Planejamento estratégico do município & 0 & 10 \\
3 & Gestão de recursos hídricos & 0 & 10 \\
4 & Disponibilidade de recursos hídricos & 0 & 10 \\
5 & Assistência técnica & 0 & 10 \\
6 & Crédito & 0 & 10 \\
7 & Cursos & 0 & 10 \\
8 & Tecnologia & 0 & 10 \\
\hline
\end{tabular}

Fonte: elaborado pelos autores

\section{CONSIDERAÇÕES FINAIS}

O objetivo deste estudo foi a proposição de um constructo de indicadores capazes de avaliar a sustentabilidade na atividade leiteira. Para essa finalidade, num primeiro momento elaborou-se um conjunto de 70 questões, com base na literatura consultada, abrangendo as dimensões econômica, social, ambiental e político institucional. Na sequência, com o uso da metodologia Delphi, fez-se o envio dos questionários aos especialistas com o fito de obter sugestões de melhoria e avaliação da pertinência dos indicadores listados. Após receber os pareceres dos especialistas, ajustes foram realizados e a versão final foi novamente submetida aos mesmos especialistas, com a nova configuração apresentada.

Quanto ao formato final do modelo proposto, denominado de Sistema de Indicadores da Sustentabilidade Bovina - SISB, este se compõe de quatro dimensões (Econômica, Social, Ambiental e Político Institucional) e 70 indicadores, que se consideram suficientes para avaliar o nível de sustentabilidade pelas quatro perspectivas citadas. Contudo, convém ressalvar que a dimensão econômica ficou com um número maior de indicadores porque na atividade leiteira, por mais que seja em pequena escala, o fator econômico tem peso maior. Entretanto, essa característica, por si só, não desequilibra o modelo sugerido porque foram atribuídos pesos distintos, conforme mencionado na seção de metodologia.

No que tange à contribuição da pesquisa, esta se orientou por estudos teóricos e empíricos acerca de modelos de indicadores capazes de mensurar a sustentabilidade na atividade leiteira, visando formatar um modelo aplicável ao referido contexto. Assim, tendo em vista que não se encontrou na literatura estudos assemelhados que envolvessem as quatro dimensões mencionadas no âmbito da atividade agropecuária desenvolvida, dessume-se que o instrumento de avaliação descrito nas seções precedentes pode ser considerado uma contribuição teórica proporcionada por esta pesquisa. Além disso, é cabível enaltecer a facilidade de aplicação do modelo sugerido, visto que foi formatado com escala do tipo likert que permite facilidade para tabulação até mesmo em planilhas Excel.

Quanto às limitações do estudo, é válido mencionar que a priori o instrumento de avaliação da sustentabilidade proposto é aplicável ao contexto da produção de leite, não tendo sido testado em outros contextos do setor agrícola. Nesse sentido, em pesquisas futuras caberia testar a aplicabilidade desta ferramenta em outros tipos de produção (suinocultura, avicultura etc.), como forma de averiguar a necessidade de adaptações.

\section{AGRADECIMENTOS}

Agradecimento à Coordenação de Aperfeiçoamento de Pessoal de Nível Superior (CAPES) pelo apoio financeiro, e à Universidade Federal de Lavras (UFLA) e à Universidade Comunitária da Região de Chapecó (UNOCHAPECÓ) por proporcionar a realização deste estudo.

\section{REFERÊNCIAS}

Ahlert, E. M. (2016). Sistema de indicadores para avaliação da sustentabilidade de propriedades produtoras de leite (Master's thesis). Dissertação de Mestrado. Programa de Pós Graduação em Ambiente e Desenvolvimento, do Centro Universitário UNIVATES, Lajeado - RS.

Banerjee, S. B. (2002). Organisational strategies for sustainable development: developing a research agenda for the new millennium. Australian journal of management, 27(1_suppl), 105-117.

Cajazeira, J. E. R. (2009). Responsabilidade social empresarial e empresa sustentável: da teoria à prática. Saraiva Educação SA.

Barreto, R. C. S. (2004). Políticas públicas e o desenvolvimento rural sustentável no Estado do Ceará: estudo de caso. Dissertação. Programa de Pós-Graduação em Economia Rural, Universidade Federal do Ceará. Fortaleza - CE. 
Baumgartner, R. J. (2014). Managing corporate sustainability and CSR: A conceptual framework combining values, strategies and instruments contributing to sustainable development. Corporate Social Responsibility and Environmental Management, 21(5), 258-271.

Bedoya, D. M. V. (2015). Análise da sustentabilidade da produção de leite: um estudo na principal bacia leiteira do Brasil (Doctoral dissertation, Universidade de São Paulo).

Belloni, I., Magalhães, H. D., \& Sousa, L. C. D. (2007). Metodologia de avaliação em políticas públicas: uma experiência em educação profissional. In Metodologia de avaliação em políticas públicas: uma experiência em educação profissional.

Broccardo, L., \& Zicari, A. (2020). Sustainability as a driver for value creation: A business model analysis of small and medium entreprises in the Italian wine sector. Journal of Cleaner Production, 259, 120852.

Capra, F., \& Eichemberg, N. R. (2006). A teia da vida: uma nova compreensão científica dos sistemas vivos. São Paulo: Cultrix.

Daly, H. E. (2014). Steady-state economics: concepts, questions, policies. Gaia-Ecological Perspectives for Science and Society, 1(6), 333-338.

Dal Soglio, F. K. (2013). Desenvolvimento, agricultura e agroecologia: qual o papel a ligação. Desenvolvimento rural sustentável no norte e sul do Brasil. Belém: PakaTatu, 197-226.

De Camargo, T. F., Zanin, A., Mazzioni, S., De Moura, G. D., \& Afonso, P. S. L. P. (2018). Sustainability indicators in the swine industry of the Brazilian State of Santa Catarina. Environment, Development and Sustainability, 20(1), 65-81.

Deponti, C. M., \& Almeida, J. (2001). Indicadores para avaliação da sustentabilidade em contextos de desenvolvimento rural local. In Congresso Da Associação Americana De Sociologia Rural (Aasr) (Vol. 4).

Di Domenico, D., Kruger, S. D., Mazzioni, S., Zanin, A., \& Ludwig, M. B. D. (2017). Índice de sustentabilidade ambiental na produção leiteira. Race: revista de administração, contabilidade e economia, 16(1), 261-282.
Dragusanu, R., Giovannucci, D., \& Nunn, N. (2014). The economics of fair trade. Journal of economic perspectives, 28(3), 217-36.

Ensslin, L., Giffhorn, E., Ensslin, S. R., Petri, S. M., \& Vianna, W. B. (2010) Avaliação do desempenho de empresas terceirizadas com o uso da metodologia multicritério de apoio à decisão-construtivista. Pesquisa Operacional,30(1), 125-152.

Elkington, J. (2012). Sustentabilidade, canibais com garfo e faca. São Paulo: M. Books do Brasil, 20.

Elkington, J. (2020). Sustentabilidade: canibais com garfo e faca. M. Books.

Evans, P. B. (2012). Embedded autonomy: States and industrial transformation. Princeton University Press.

Freeman, R. E., \& Dmytriyev, S. (2017). Corporate social responsibility and stakeholder theory: Learning from each other. Symphonya. Emerging Issues in Management, (1), 7-15.

Foladori, G. (2002). Avances y límites de lasustentabilidad social. n (12), 621-637,

Gadotti, M. (2012). Educar para a sustentabilidade., v. 3, n (1), 75-78.

Garcia, D. S. S. (2012). A atividade portuária como garantidora do Princípio da Sustentabilidade. Revista de Direito Econômico e Socioambiental, 3(2), 375-399.

Garcia, D. S. S., \& Garcia, H. S. (2014). Dimensão social do princípio da sustentabilidade: uma análise do mínimo existencial ecológico. Lineamentos sobre sustentabilidade segundo Gabriel Real Ferrer-Dados eletrônicos.-Itajai: UNIVALI.

Giordano, S. R. (2005) Gestão ambiental no sistema agroindustrial. In. ZYLBERSZTAJN, Décio; NEVES, Marcos Fava (org.). Economia \& gestão dos negócios.

Gomes, I. (2005). Sustentabilidade social e ambiental na agricultura familiar. Revista de biologia e ciências da terra, 5(1), 0 .

Hallstedt, S. I. (2017). Sustainability criteria and sustainability compliance index for decision support in product development. Journal of Cleaner production, 140, 251-266. 
IBGE. Instituto Brasileiro de Geografia e Estatística. Indicadores de desenvolvimento sustentável: Brasil 2012. Estudos e Pesquisas. Informações Geográficas, Rio de Janeiro: IBGE, n. 9, 2012.

Kimpara, J. M., Zajdband, A. D., \& Valenti, W. C. (2010). Medindo a sustentabilidade na aquicultura. Boletim da Sociedade Brasileira de Limnologia. v.38, n.2, 01-72.

Larsen, G. L. (2008). An inquiry into the theoretical basis of sustainability: Ten propositions. In Understanding the social dimension of sustainability (pp. 61-98). Routledge.

Lüdeke-Freund, F., Freudenreich, B., Schaltegger, S., Saviuc, I., \& Stock, M. (2017). Sustainability-oriented business model assessment-A conceptual foundation. In Analytics, innovation, and excellence-driven enterprise sustainability (pp. 169-206). Palgrave Macmillan, New York.

Magis, K., \& Shinn, C. (2008). Emergent principles of social sustainability. In Understanding the social dimension of sustainability (pp. 31-60). Routledge.

Lima, M. A. B. (2005). Avaliação de impactos de investimentos públicos em ciência e tecnologia sobre o desenvolvimento regional. Tese de Doutorado. Programa de PósGraduação em Economia da Universidade Federal do Rio Grande do Sul. Porto Alegre.

Nascimento, E. P. D. (2012). Trajetória da sustentabilidade: do ambiental ao social, do social ao econômico. Estudos avançados, 26(74), 51-64.

Peruzatto, M. (2009). Avaliação de desempenho de granjas suinícolas pelo emprego de indicadores de sustentabilidade. Dissertação (mestrado). Programa de PósGraduação em Engenharia Civil. Universidade do Vale do Rio dos Sinos.

Ramos, D., Afonso, P., \& Rodrigues, M. A. (2020). Integrated management systems as a key facilitator of occupational health and safety risk management: A case study in a medium sized waste management firm. Journal of Cleaner Production, 262, 121346.

Rede Interagencial De Informação Para A Saúde (Ripsa). Indicadores básicos para a saúde no Brasil: conceitos e aplicações. 3. ed. Brasília: Organização PanAmericana da Saúde, 2013.
Rempel, C., Eckhardt, R. R., Jasper, A., Schultz, G., Hilgert, Í. H., \& Barden, J. E. (2012). Proposta metodológica de avaliação da sustentabilidade ambiental de propriedades produtoras de leite. Tecno-Lógica, 16(1), 48-55.

Ribeiro, R. D. C. (2015). Desenvolvimento rural sustentável e agricultura familiar: diagnóstico participativo de indicadores econômicos, sociais e ambientais na região Oeste do Paraná.Dissertação de Mestrado. Programa de Pós Graduação em Desenvolvimento Rural Sustentável do Centro de Ciências Agrárias da Universidade Estadual do Oeste do Paraná - UNIOSTE. Marechal Candido Rondon.

Sachs, I. (2009). Caminhos para o desenvolvimento sustentável. Editora Garamond.

Sama, C., Crespo-Cebada, E., Díaz-Caro, C., Escribano, M., \& Mesías, F. J. (2018). Consumer Preferences for Foodstuffs Produced in a Socio-environmentally Responsible Manner: A Threat to Fair Trade Producers?. Ecological Economics, 150, 290-296.

Sen, A. (2018). Desenvolvimento como liberdade. Editora Companhia das letras.

Silva, J. A. D. (2013). Direito ambiental constitucional. atual. São Paulo: Malheiros, 73.

Silva, J. D. S., Cheaz, J., \& Romero, J. (2001). La dimensión institucional del desarrollo sostenible. Pontificia Universidad Católica del Ecuador sede Ibarra (PUCE-I).

Silva, M. R. D. (2015). Avaliação da sustentabilidade dos agroecossistemas de agricultores familiares que atuam na feira-livre de Pato Branco-PR (Master's thesis, Universidade Tecnológica Federal do Paraná).

Sitorus, F., \& Brito-Parada, P. R. (2020). A multiple criteria decision making method to weight the sustainability criteria of renewable energy technologies under uncertainty. Renewable and Sustainable Energy Reviews, 127, 109891.

Spangenberg, J. H., Pfahl, S., \& Deller, K. (2002). Towards indicators for institutional sustainability: lessons from an analysis of Agenda 21. Ecological indicators, 2(1-2), 61-77.

Spínola, A. W. D. P. (1984). Delfos: proposta tecnológica alternativa; ediçäo preliminar. 
Spies A. (2014) Perspectivas e desafios para o desenvolvimento da cadeia produtiva na região sul do Brasil. Dezembro.

Van Bellen, H. M. (2006). Indicadores de sustentabilidade: uma análise comparativa. FGV editora.

Verona, L. A. F. (2008). Avaliação de sustentabilidade em agroecossistemas de base familiar e em transição agroecológica na região sul do Rio Grande do Sul.

Vilela, D.; Bressan, M.; Gomes, A. T.; Leite, J. L. B.; Martins, M. C.; Netto, V. N. (2002). Agronegócio do leite e politicas públicas para o seu desenvolvimento sustentável. Embrapa Gado de Leite.

Yamaguchi, L., Oliveira, A. D., \& Martins, P. D. C. (2005). Gestão da informação como fator de competitividade na produção de leite. Tecnologia e gestão na atividade leiteira. Juiz de Fora: Embrapa Gado de Leite.
Wiesenfeld, E. (2003). La Psicología Ambiental y el desarrollo sostenible. Cuál psicología ambiental? Cuál desarrollo sostenible?. Estudos de Psicologia (Natal), 8(2), 253-261.

Wright, J. T., Giovinazzo, R. A., Wright, J., \& Giovinazzo, R. (2000). Delphi-uma ferramenta de apoio ao planejamento prospectivo.

Zanin, A., Dal Magro, C. B., Mazzioni, S., \& Afonso, P. (2019). Triple Bottom Line Analysis in an Agribusiness Supply Chain. In International Joint conference on Industrial Engineering and Operations Management (pp. 264-273). Springer, Cham.

Zanin, A., Dal Magro, C. B., Kleinibing Bugalho, D., Morlin, F., Afonso, P., \& Sztando, A. (2020). Driving sustainability in dairy farming from a TBL perspective: insights from a case study in the West Region of Santa Catarina, Brazil. Sustainability, 12(15), 6038.

Organizações Rurais \& Agroindustriais, Lavras, v. 23, e1629, 2021 